\title{
Microbiological Screening and Antimicrobial Sensitivity Profiling of Wound Infections in a Tertiary Care Hospital of Bangladesh
}

\author{
Abdullah Akhtar Ahmed ${ }^{1 \& 2}$, Nusrat Akhtar Juyee ${ }^{3}$, S.M. Ali. Hasan ${ }^{4}$, and Mohammad Zakerin Abedin ${ }^{1 *}$ \\ ${ }^{1}$ Dept. of Microbiology, Khwaja Yunus Ali University, Sirajganj, Bangladesh; ${ }^{2}$ Dept. of Microbiology, Khwaja Yunus Ali \\ Medical College, Sirajganj, Bangladesh; ${ }^{3}$ Dept. of Microbiology and Immunology, Bangabandhu Sheikh Mujib Medical \\ University, Dhaka, Bangladesh; and ${ }^{4}$ Dept. of Gastroenterology, Bangabandhu Sheikh Mujib Medical University, Dhaka, \\ Bangladesh. \\ *Correspondence: zakerin.du2016@gmail.com (Mohammad Zakerin Abedin, Assistant Professor and Head, Dept. of \\ Microbiology, Khwaja Yunus Ali University, Sirajganj, Bangladesh).
}

\begin{abstract}
Wound infection is a major problem in hospitals in developing countries. Wound infection causes morbidity and prolonged hospital stay thus this prospective study was conducted for a period of seven months (January 2019 to July 2019). A total of 217 specimens (wound swabs and pus exudates) from wound infected patients in a Tertiary Care Hospital in Bangladesh. A retrospective study of the microbiological evaluation was done by cultural growth as well as Gram staining and biochemical examination to identify the bacterial isolates. Finally, the antimicrobial vulnerability testing was performed by Kirby-Bauer disc diffusion conventional method. A total of 295 samples were tested. Out of which 217 (73.5\%) were found culture positive. E. coli was the most predominant gram-negative isolates whereas Staphylococcus aureus and Coagulase-negative Staphylococcus were the most commonly isolated gram-positive organisms. Antimicrobial sensitivity profile of bacterial isolates revealed imipenem, meropenem, amikacin, and nitrofurantoin to be the most effective antimicrobials against gram-negative isolates, whereas imipenem, meropenem, amikacin, nitrofurantoin, amoxiclav, and gentamicin were the most effective drugs against gram-positive isolates. The result of this examination contributes to the identification of basic causative microbes involved in wound infection and findings of antibiotic susceptibility patterns can be helpful for primary care physicians to optimize the treatment modalities, articulate policies for empiric antimicrobial therapy, and to minimize the rate of infection among wound infected patients.
\end{abstract}

Keywords: Staphylococcus aureus, Screening, Pseudomonas aeruginosa, and Antimicrobial sensitivity profiling.

\section{INTRODUCTION:}

The wound infection is known as the presence and growth of microbes in wound (Howell-Jones et al., 2005). The development of wound infection depends on the integrity and prospective function of skin (Sorg et al., 2017). The local wound conditions, systemic host defenses, microbial burden, and existing ailments just as outward factors, for example, pre, intra and UniversePG I www.universepg.com postoperative care are the potential variables for infection of a patient. Along these lines, it is hard to foresee which wound will get infected. The general frequency of wound sepsis is from 10-33\% (Neelima et al., 2013). Relative protection from anti-microbials nearly more harmful strains and ability to adjust rapidly to changing climate make the microorganisms obtained in medical clinics a matter of concern 
(Plummer et al., 2004). Notwithstanding current careful methods and the utilization of anti-infection prophylaxis, Surgical Site Infection (SSI) is one of the most widely recognized intricacies experienced in medical procedure. SSI places a critical significant on both the patient and wellbeing framework. SSI is thus a major cause of morbidity, prolonged hospital stay and increased health costs (Mezemir et al., 2020)

Wound infection therapy with antibiotics and ideal treatment regimens remains under documented. There are many published guidelines are for the most part dependent on expert conclusion instead of proof based information. The choice of appropriate antimicrobial drugs has been uncertain. Despite the fact that prophylactic utilization of antimicrobials can help decrease the danger of disease and advances wound mending, it's anything but an immediate substitute for good nearby twisted consideration, for example, water system and careful debridement. In addition, supported utilization of antimicrobials decreases the improvement of antimicrobial obstruction (AMR) (Elbur et al., 2013; Rijal et al., 2017).

It has been revealed by reviewing of recent practices that potentially inappropriate and inconsistent use of antimicrobials following surgical procedures contributes to development of AMR. Likewise, fittingness of the circumstance, the span, course, and determination of these agents stays elusive (Tweed et al., 2005 and Landis et al., 2008). In Bangladesh, the efficient review and Meta analysis is planned to give cross country pooled estimates of microbial profiles, wound culture positivity, and AMR patterns of wound disease. This will manage as a benchmark for creating antimicrobial reconnaissance programs and producing proof based determination of antimicrobials to protect the accessible antimicrobials and contain AMR.

\section{METERIALS AND METHODS:}

Study Place - This study was conducted in Microbiology section of the Department of Laboratory Services, Khwaja Yunus Ali Medical College Hospital of remote region Enayetpur of Bangladesh from January 2019 to July 2019.

Sample Collection and Processing - All the wounds were judged as infected by the presence of purulent UniversePG I www.universepg.com material. Before wound cleansing and dressing conducted pus discharge from 92 and wound swab from 203 patients were collected. Two wound swabs were collected from the wound and from a drop of aspirate using sterile cotton tipped applicators. First swab used to make smear on a clean glass slides and Gram staining was done for direct microscopic examination at 100X objective to know details bacteria-l morphology and leucocytes cells.

Isolation and Identification - The second swab or drop of aspirate pus was utilized for culture by sterile inoculating loop on routine laboratory culture media like Nutrient Agar, Blood Agar, and MacConkey's agar, and then incubated at $37^{\circ} \mathrm{C}$ for $24 \mathrm{hrs}$ to 48 hours aerobically.

Isolates were confirmed on standard microbiological methods. They included morphological and cultural characteristics, Gram staining, motility, hydrogen sulphide production, indole production, carbohydrate fermentation test, and Simon citrate utilization test. Other tests include catalase test, oxidase test, coagulase, haemolysis on blood agar, morphological and cultural characteristics on eosin-methylene blue agar, and mannitol salt agar.

Antibiotic Sensitivity - The antibiotic sensitivity pattern was done by Potentiated Disc Diffusion Test (PDT) using Muller Hinton agar through following Kirby Bauer's method as per standard CLSI guidelines (CLSI 2017). Commonly used antibiotics (Oxoid antibiotic disc, UK) were tested against both of both Gram positive and Gram negative bacterial isolates.

Exclusion Criteria - Patients already on antibiotics were excluded from the study

Data Analysis - The SPSS version 16.0 was used for analysis of data. The percentage of frequencies were generated for different categorical variables such as rate of isolation, type of bacteria, rate of antibiotic sensitivity, resistance, intermediate of the organisms.

\section{RESULTS:}

A total of 295 samples received in the laboratory were randomly selected for this study. Out of which 217 samples showed aerobic growth, and 78 remained sterile even after 48 hours incubation at $37^{\circ} \mathrm{C}$. Among 
217 growth positive cases, $203(68.8 \%)$ samples were from swab and 29 (37.2\%) were from aspirate (Table from pus swab and 92 (31.2\%) were from aspirate. 1 and Fig 1).

Among 78 negative cases, 49 (62.8\%) samples were

Table 1: Frequency of growth and no growth patterns in total wound samples.

\begin{tabular}{|l|l|l|l|l|l|}
\hline \multirow{2}{*}{ Types of sample } & \multicolumn{2}{|l|}{ Growth } & No Growth & \multirow{2}{*}{ Total number (\%) } \\
\cline { 2 - 5 } & Number (N) & Percent & Number (N) & Percent & \\
\hline Pus swab & 154 & $75.9 \%$ & 49 & $24.1 \%$ & $203(68.8 \%)$ \\
\hline Pus aspirate & 63 & $68.5 \%$ & 29 & $31.5 \%$ & $92(31.2 \%)$ \\
\hline Total positive cases & 217 & Total negative cases & 78 & & $295(100 \%)$ \\
\hline
\end{tabular}

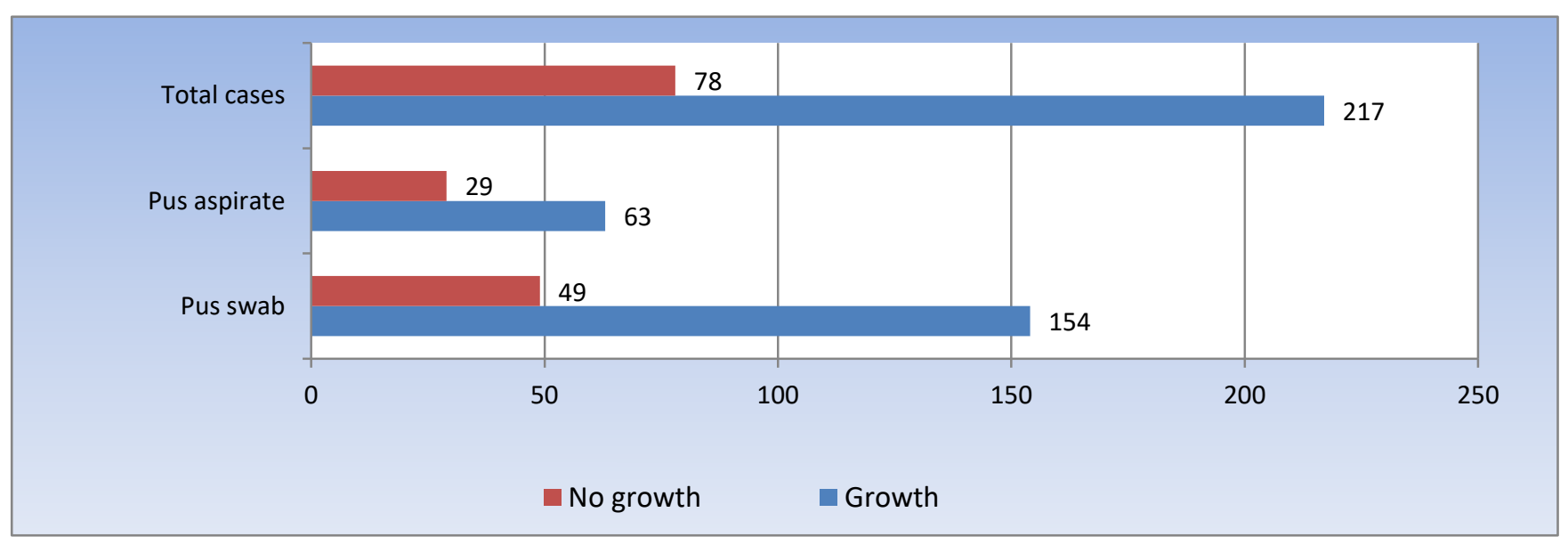

Fig 1: Total number of frequency of wound infection of the suspected patients.

Table 2: Distribution Pattern of Bacterial Isolates of wound infection $(n=217)$.

\begin{tabular}{|l|l|l|l|}
\hline Bacterial isolates & & Total No. & Percentage \\
\hline \multirow{5}{*}{ Gram negative bacteria $\mathrm{n}=121(55.8 \%)$} & Escherichia coli & 89 & 41 \\
\cline { 2 - 4 } & Pseudomonas aureginosa & 26 & 12 \\
\cline { 2 - 4 } & Klebsiella spp & 06 & 3 \\
\hline \multirow{2}{*}{ Gram positive bacteria $\mathrm{n}=96(44.2 \%)$} & Staphylococcus aureus & 68 & 31 \\
\cline { 2 - 4 } & Coagulase Negative Staphylococcus & 28 & 13 \\
\hline Total & & 217 & 100 \\
\hline
\end{tabular}

Majority of the wound was infected with single organism. A Gram negative Bacillus was $55.8 \%$ and Gram positive Cocci $44.2 \%$. Most frequently isolated organisms were E. coli, 89(41\%) followed by Staphylococcus. aureus 68(31\%), Coagulase negative Staphylococcus, other isolates included Klebsiella spp 6(3\%) and Pseudomonas aureginosa 26(12\%), (Table 2).

High number of samples (45) were collected from patients of age group 41 - 50 years and the least i.e. 09 samples were obtained from patients of age group 0 10 years. Among 217 positive cases, the highest posi- tive cases $118(54.4 \%)$ were male and rest 99 (45.6\%) were female (Table 3).

Antibiotic susceptibility pattern of the isolates showed imipenem 202 (93.1\%), meropenem 175 (80.6\%) and amikacin $166(76.5 \%)$ were found effective for both Gram-negative and Gram-positive isolates (Shahen et al., 2019). Cephradine 48 (22.1\%) was found to be weak in inhibiting both Gram-positive and gramnegative bacterial growth. For Gram-negative isolates Cephradine showed highest resistant pattern (Table 4). 
Table 3: Gender and age-wise distribution of wound infected patients $(n=217)$.

\begin{tabular}{|c|c|c|c|c|c|c|}
\hline \multirow{2}{*}{$\begin{array}{c}\text { Age group } \\
\text { (in years) }\end{array}$} & \multicolumn{2}{|c|}{ Male } & \multicolumn{2}{|c|}{ Female } & \multirow{2}{*}{$\begin{array}{c}\text { Total } \\
\text { (no. of cases) }\end{array}$} & \multirow{2}{*}{$\begin{array}{c}\text { Percentage } \% \\
\quad(n=217)\end{array}$} \\
\hline & No. of cases & $\%$ age & No. of cases & $\%$ age & & \\
\hline $0-10$ & 5 & 4.2 & 4 & 4.1 & 9 & 4.0 \\
\hline $11-20$ & 8 & 6.8 & 11 & 11.1 & 19 & 8.7 \\
\hline $21-30$ & 23 & 19.5 & 23 & 23.2 & 46 & 21.1 \\
\hline $31-40$ & 19 & 16.1 & 22 & 22.2 & 41 & 19.0 \\
\hline $41-50$ & 31 & 26.3 & 14 & 14.1 & 45 & 21.0 \\
\hline $51-60$ & 22 & 19.4 & 16 & 16.2 & 38 & 17.5 \\
\hline$>60$ & 10 & 8.5 & 9 & 9.1 & 19 & 8.7 \\
\hline Total & 118 & 54.4 & 99 & 45.6 & 217 & 100 \\
\hline
\end{tabular}

Table 4: Antimicrobial sensitivity profile of bacterial isolates from the wound patients.

\begin{tabular}{|l|l|l|l|l|l|l|}
\hline \multirow{2}{*}{ Antibiotics } & \multicolumn{6}{|c|}{ Bacterial isolates, Number (n) with percentage (\%) } \\
\cline { 2 - 7 } & $\begin{array}{l}\text { E.coli } \\
\mathbf{8 9}(\mathbf{4 1})\end{array}$ & $\begin{array}{l}\text { S. aureus } \\
\mathbf{6 8}(\mathbf{3 1})\end{array}$ & $\begin{array}{l}\text { NoSA } \\
\mathbf{2 8}(\mathbf{1 3})\end{array}$ & $\begin{array}{l}\text { P. aureginosa } \\
\mathbf{2 6}(\mathbf{1 2})\end{array}$ & $\begin{array}{l}\text { Klebsiella } \\
\text { spp 06 (3) }\end{array}$ & $\begin{array}{l}\text { Total } \\
\mathbf{2 1 7}(\mathbf{1 0 0})\end{array}$ \\
\hline Amoxiclav & $22(24.7)$ & $40(58.8)$ & $20(71.4)$ & $04(15.3)$ & $04(66.6)$ & $90(41.5)$ \\
\hline Amikacin & $60(67.4)$ & $58(85.2)$ & $24(85.7)$ & $19(73)$ & $05(83.3)$ & $166(76.5)$ \\
\hline Azithromycin & $18(20.2)$ & $13(19.1)$ & $07(25)$ & $15(57.6)$ & $03(83.3)$ & $56(25.8)$ \\
\hline Ceftazidime & $21(23.5)$ & $17(25)$ & $17(60.7)$ & $19(73)$ & $04(66.6)$ & $78(35.9)$ \\
\hline Ceftriaxone & $21(23.5)$ & $30(44.1)$ & $20(71.4)$ & $18(69.2)$ & $03(83.3)$ & $92(42.4)$ \\
\hline Cefuroxin & $15(16.8)$ & $28(41.1)$ & $20(71.4)$ & $02(7.7)$ & $02(33.3)$ & $67(30.8)$ \\
\hline Cephradine & $05(5.6)$ & $23(33.8)$ & $17(60.7)$ & $02(7.7)$ & $01(16.6)$ & $48(22.1)$ \\
\hline Ciprofloxacin & $17(19.1)$ & $25(36.7)$ & $13(46.4)$ & $16(61.5)$ & $04(66.6)$ & $75(34.5)$ \\
\hline Gentamicin & $36(40.40$ & $40(58.8)$ & $27(96.4)$ & $14(53.8)$ & $05(83.3)$ & $122(56.2)$ \\
\hline Imipenem & $79(88.7)$ & $65(95.5)$ & $28(100)$ & $23(88.4)$ & $06(100)$ & $202(93.1)$ \\
\hline Meropenem & $68(76.4)$ & $56(82.3)$ & $23(82.1)$ & $23(88.4)$ & $05(83.3)$ & $175(80.6)$ \\
\hline Levofloxacin & $18(20.2)$ & $31(45.5)$ & $13(46.4)$ & $16(61.5)$ & $05(83.3)$ & $83(38.2)$ \\
\hline Nitrofurantoin & $48(53.9)$ & $46(67.6)$ & $23(82.1)$ & $04(15.3)$ & $02(33.3)$ & $123(56.7)$ \\
\hline
\end{tabular}

\section{DISCUSSION:}

Wound contamination has been a significant worry among medical services specialists not just regarding expanded injury to the patient yet additionally taking into account its weight on money related assets and the expanding necessity for savvy the board inside the medical care framework. To take care of the serious issue of medical care framework this investigation is completed to discover the bacteriological profile of wound contaminations and antimicrobial power lessness example of secludes. It was seen that the commonest age bunch influenced is 21-30 years which are connected with the examinations done by Malik et al., 2011 and Afroz et al ., 2015. Regarding the sex distribution of the patients in the present study, males $(54.4 \%)$ were affected more than females (45.6\%). The possible reasons for this male preponderance can be related to socio-economic and cultural habits of 
earning the livelihood primarily by males and also to their adventurous nature and the greater desire to be active in comparison to their female counterparts (KaiYang et al., 2008). This study was correlated with Ramesh et al. (2013) which showed males (60\%) more affected than females, Sowmya et al. (2014) (66.6\%) and Malik et al. (2011) (51.9\%) also showed the predominance of males over females.

In this study on wound infection five different types of organisms were identified. Highest percentage of isolation was Escherichia coli (41\%), followed by Staphylococcus aureus (31\%), Coagulase Negative Staphylococcus (13\%), Pseudomonas aeruginosa (12\%) and Klebsiella pneumoniae (3\%). Similarly, Escherichia coli $(55.9 \%)$ in highest percentage were detected in Dhaka, Bangladesh study on wound infection where four different types of organisms were identified (Atiyeh et al., 2007). However, Staphylococcus aureus (27.5\%) was found as the most common isolate followed by CoNS $(8.5 \%)$, (Tapan et $a l ., 2013)$. The antibiogram studies indicate the emergence of extensively drug resistant and pandrug resistant strains. The isolates were exhibited resistance to the commonly used antibiotics as well as new generation antibiotics. In our study, most of the isolated pathogens were found sensitive to costly antibiotics like Imipenem (93.1\%), followed by Meropenem (80.6\%), Amikacin (76.5\%) and least effective cheap antibiotics were Ampicillin, Amoxi-cillin, Cefixim and Cefotaxime. Amikacin was also found highly sensitive to wound infection pathogens by Neelima et al. 2013. In contrast to our study, the incidence of resistant to Meropenem (83.78\%), Imipenem $(85.41 \%)$ and Amikacin $(87.03 \%)$ were found by Abedin et al. (2020).

\section{CONCLUSION:}

This experiment was completed to decide bacteriological and antimicrobial affectability profile of wound contaminations in a tertiary care hospital of Bangladesh. This study may update the physicians in the different antimicrobial choices accessible in the treatment of wound diseases, consequently assisting with diminishing morbidity and mortality in long haul; it might decrease the expense of treatment. In our investigation assortment of aerobic bacteria are UniversePG I www.universepg.com isolated from wound with prevalence of Escherichia coli followed by Staphylococcus aureus. Imipenem was the most delicate medication among both Gram positive and Gram negative bacteria and later on Amikacin and Ceftazidime was least effective (Abedin et al., 2020). It tends to be concluded that more complete investi-gations are needed every once in a while to characterize the extent of issue and produce information for strategy choice on ideal mediation modalities.

\section{ACKNOWLEDGEMENT:}

We acknowledge the stuff of the Department of Laboratory Services, Khwaja Yunus Ali Medical College Hospital and Department of Microbiology, School of Biomedical Science, Khwaja Yunus Ali University, Sirajganj, Bangladesh.

\section{CONFLICTS OF INTEREST:}

Authors declare that no competing interest exists to publish the present research work.

\section{REFERENCE:}

1. Abedin MZ et al. (2020). Enumeration of the antimicrobial susceptibility patterns of differrent bacterial isolates from ENT patients with ear infections, Eur. J. Med. Health Sci., 2(4), 68-73.

https://doi.org/10.34104/ejmhs.020.068073

2. Abedin MZ, Aktar MB, Zaman MSU, Jarin L, Miah MAS, and Ahmed AA, et al. (2020). Predominance of nosocomial pathogens among patients with post-operative wound infections and evaluation of the anti-biotic susceptibility patterns in rural hospi-tals in Bangladesh. Recent Adv Biol Med.; 6(4): 9800005.

https://doi.org/10.18639/RABM.2020.9800005

3. Afroz Z, Metri BC, Jyoti P. (2015). Bacteriological Profile and Antimicrobial Susceptibility Pattern of Skin and Soft Tissue Infections among Gram Negative Bacilli in a Tertiary Care Hospital of South India. J. Pharm. Scie \& Res. 7(7): 397-400.

https://www.jpsr.pharmainfo.in/Documents/Vol umes/vol7Issue07/jpsr07071502.pdf 
4. Atiyeh BS et al. (2007). Effect of silver on burn wound infection control and healing: review of the literature. Burns. 33(2): 139-48. https://doi.org/10.1016/j.burns.2006.06.010

5. CLSI, (2017). Performance Standards for antimicrobial susceptibility testing, twenty-third information supplement. M100-S24. 34: 5057.

6. Elbur AI, Yousif M, Abdel-Rahman ME. (2013). Prophylactic antibiotics and wound infection. J Clin Diagn Res. 7(12): 2747.

7. Howell-Jones RS et al. (2005). A review of the microbiology, antibiotic usage and resistance in chronic skin wounds, Journal of Antimicrobial Chemotherapy. 55(2): 143-149. https://doi.org/10.1093/jac/dkh513

8. Landis SJ. (2008). Chronic wound infection and antimicrobial use. Adv Skin Wound Care. 21(11): 531-40.

9. Malik S, Gupta A, Singh KP, Agarwal J, Singh M. (2011). Antibiogram of Aerobic Bacterial Isolates from Post Operative wound Infections at a Tertiary Care Hospital in India. J. Infect. Dis-Antimicriob Agents. 28; 45-51.

10. Mezemir, R., Seid, A., Gishu, T., Demas, T., $\&$ Gize, A. (2020). Prevalence and root causes of surgical site infections at an academic trauma and burn center in Ethiopia: a crosssectional study. Patient safety in surgery, 14, 3. https://doi.org/10.1186/s13037-019-0229-x

11. Neelima et al. (2013). Bacteriological profile of wound infection in rural hospital in R.R District. Int J Med Res Heal Sci. 2(3):469-473.

12. Olson M et al. (1984). Surgical wound infections of 5 year prospective study of 20, 193 wounds at Minneapolis Va Medical Centre. Ann Surg. 199(3): 253-259.

13. Plummer D. (2004). Surgical Wound infections as a performance indicator: agreement of common definitions of wound infections in 4773 patients. BMJ. 329: 720-22. https://doi.org/10.1136/bmj.38232.646227.DE

14. Rao R et al., (2013). Bacteriology of PostOperative wound infections. Int. J. Pharm Biomed Res. 4(2), 72-76.

15. Rijal BP, Satyal D, Parajuli NP. (2017). High burden of antimicrobial resistance among Bacteria causing pyogenic wound infections at a tertiary Care Hospital in Kathmandu, Nepal. J Pathogens. 2017: 7.

16. Shahen MZ, Mahmud S, Uddin ME and Alam MS. (2019). Effect of antibiotic susceptibility and inhibitory activity for the control of growth and survival of microorganisms of extracts of Calendula officinalis, Eur. J. Med. Health Sci. 1(1), 1-9. https://doi.org/10.34104/ejmhs.0190109

17. Sorg H, Tilkorn D, J, Hager S, Hauser J, Mirastschijski U. (2017). Skin Wound Healing: An Update on the Current Knowledge and Concepts. Eur Surg Res. 58: 81-94. https://doi.org/10.1159/000454919

18. Sowmya N et al. (2014). A two-year study of spectrum of bacterial isolates from wound infections by aerobic culture and their antibiotic pattern in a tertiary care centre. Int. J.Cure. Microbiol, App. Sci. 3(8): 292-295.

19. Tapan Kr Mandal, Rajeshwari Surpur, Achut Rao, (2013). Dept. Of Microbiology, Navoday Medical College, Raichur: $36^{\text {th }}$ National conference souvenir. Pp. 108.

20. Tweed C. (2005). Prevention of surgical wound infection: prophylactic antibiotics in colorectal surgery. J Wound Care. 14(5): 202-5.

21. Yang KL et al. (2008). Epidemiology of pediatric burns requiring hospitalization in China: a literature review of retrospective studies. Pediatrics, 122: 132-42. https://doi.org/10.1542/peds.2007-1567

Citation: Ahmed AA, Juyee NA, Hasan SMA, and Abedin MZ. (2020). Microbiological screening and antimicrobial sensitivity profiling of wound infections in a tertiary care hospital of Bangladesh, Eur. J. Med. Health Sci., 2(5), 101-106. https://doi.org/10.34104/ejmhs.020.01010106 C) 